\title{
(1) Carbimazole-induced Antineutrophil Cytoplasmic Antibody (ANCA) positive vasculitis: A case report
}

\author{
KF Wong', V Baskar', A Viswanath', HN Buch' \\ 'Wolverhampton Diabetes and Endocrine Centre, New Cross Hospital, \\ Wolverhampton WV10 OQP
}

\section{Introduction:}

- Vasculitis is a rare complication of anti-thyroid medications.

- More common with Propylthiouracil than Carbimazole (Gunton et al).

- Higher incidence among the Asian and female population (Noh et al).

- Variable presenting symptoms with multisystem involvement; renal and dermatological manifestations are the commonest with less common involvement of musculoskeletal system, respiratory system and eyes (Gunton et al).

- Confirmation of diagnosis is usually on the basis of clinical findings, presence of ANCA and biopsy of involved organ.

\section{Case History:}

- A 68 year-old Caucasian man presented with fever, heat intolerance and weight loss. He was clinically and biochemically thyrotoxic with T4 37.3pmol// (8-19pmol/I) and TSH $<0.01 \mathrm{mU} / \mathrm{l}$ (0.35$4.9 \mathrm{mU} / \mathrm{I})$. There was no evidence of systemic sepsis.

- Aetiology of thyrotoxicosis was unclear but was presumed to be due to Graves' disease and he was initiated on Carbimazole 40mg once daily.

- 3 weeks later he complained of diffuse erythematous skin rash affecting his trunk and limbs with typical features of vasculitic rash.

- Laboratory investigations were as per table.

- Histological diagnosis proved difficult as both skin biopsy and renal biopsy results were inconclusive.

- Carbimazole was discontinued at the time of initial presentation and thyrotoxicosis was managed with $800 \mathrm{MBq}$ of radioiodine (RAI) along with beta blockers under close supervision.

- Despite withdrawal of carbimazole and promptly achieving euthyroidism following RAI therapy (on thyroxine) his clinical condition deteriorated with anorexia, weakness and weight loss. Renal function deteriorated progressively and he was in renal failure.

- Despite inconclusive histological diagnosis, in view of constellation of typical skin lesion, newonset renal failure, raised inflammatory markers and high myeloperoxidase ANCA titre, diagnosis of carbimazole-induced vasculitis was made.

- He was commenced on intravenous methylprednisolone 500mg for 3 days followed by oral corticosteroids.

- Over the past 4 months he has remained in renal failure, although his renal function has stabilised and he has not required dialysis. Repeat ANCA titre is negative.

Table
\begin{tabular}{|l|c|c|c|}
\hline & Presentation & 4 weeks & 3 months \\
\hline Urea (2.5-7.8 mmol/l) & 8.3 & 21 & 16.9 \\
\hline Creatinine (60-120 umol/I) & 6.0 & 194 & 218 \\
\hline ESR (<12 mm/hr) & - & 73 & 47 \\
\hline $\begin{array}{l}\text { Myeloperoxidase ANCA } \\
\text { antibody (0-3.5 IU/ml) }\end{array}$ & - & 36 & Negative \\
\hline $\begin{array}{l}\text { Rheumatoid factor (0-20 IU/ } \\
\text { ml) }\end{array}$ & - & 227 & 127 \\
\hline $\begin{array}{l}\text { Anti-nuclear antibody } \\
\text { Proteinase-3 ANCA antibody }\end{array}$ & - & Positive & $\begin{array}{c}\text { Weak } \\
\text { positive }\end{array}$ \\
\hline ENA antibody & - & Negative & Negative \\
\hline
\end{tabular}

\section{Discussion}

We have presented a case who developed typical clinical features of vasculitis 3 weeks following initiation of carbimazole for thyrotoxicosis. The diagnosis was made on clinical grounds supported by biochemical and immunological abnormalities despite inconclusive histology. Literatures suggested higher incidence of vasculitis associated with higher carbimazole dosage (generally above $15 \mathrm{mg}$ per day). Time of onset varies and literature suggested median time of onset was 42 months (Noh et al).

Presenting symptoms with dermatological and renal manifestations were as described in the literature. Immunological abnormalities were also typical with positive MPO-ANCA antibody and ANA antibody as described in literature (Gunton et al). The presence of antibody as well as antibody titre does not reflect severity of vasculitis.

Literatures review (Wiik et al and Noh et al) suggested that drug induced vasculitis usually resolve following withdrawal of the offending agent. Radic et al suggested intensive immunosuppressive therapy in managing severe and active organ involvement. In this case, despite prompt withdrawal of carbimazole and initiating high dose steroids followed by maintenance dose oral prednisolone, there has been irreversible progression of his kidneys injury. There has been small number of mortality cases in propylthiouracil induced vasculitis in the literatures but none has been reported so far in carbimazole use.

\section{References:}

Gunton JE, Stiel J, Clifton-Bligh P, et al. Prevalence of positive antineutrophil cytoplasmic antibody (ANCA) in patients receiving antithyroid medication. Eur J Endocrinol 2000; 142:587-96.

Noh JY, Yosuda S, Matsumoto M et al. Clinical characteristics of myeloperoxidase antineutrophil cytoplasmic antibody-associated vasculitis caused by antithyroid drugs. J Clin Endocrinol Metab. 2009 Aug;94(8):2806-11. doi: 10.1210/jc.2008-270 Radic M, Martinovi'c Kaliterna C. Drug-induced vasculitis: a clinical and pathological review. The Netherlands journal of medicine, 2012;70: Wiik A. Drug-induced vasculitis. Curr Opin Rheumatol. 2008;20:35-9. 